\title{
Non-standard amino acid incorporation into proteins using Escherichia coli cell-free protein synthesis
}

\author{
Seok Hoon Hong ${ }^{1,2}$, Yong-Chan Kwon ${ }^{1,2}$ and Michael C. Jewett ${ }^{1,2,3,4 *}$ \\ ${ }^{1}$ Chemical and Biological Engineering, Northwestern University, Evanston, IL, USA \\ ${ }^{2}$ Chemistry of Life Processes Institute, Northwestern University, Evanston, IL, USA \\ ${ }^{3}$ Robert H. Lurie Comprehensive Cancer Center, Northwestern University, Chicago, IL, USA \\ ${ }^{4}$ Institute of Bionanotechnology in Medicine, Northwestern University, Chicago, IL, USA
}

\section{Edited by:}

Carissa M. Soto, Naval Research

Laboratory, USA

Reviewed by:

Irina Bakunina, Russian Academy of

Sciences, Russia

Wenshe R. Liu, Texas A\&M

University, USA

*Correspondence:

Michael C. Jewett, Chemical and Biological Engineering,

Northwestern University, 2145

Sheridan Road, Tech E-136,

Evanston, IL 60208-3120, USA

e-mail:m-jewett@northwestern.edu
Incorporating non-standard amino acids (NSAAs) into proteins enables new chemical properties, new structures, and new functions. In recent years, improvements in cell-free protein synthesis (CFPS) systems have opened the way to accurate and efficient incorporation of NSAAs into proteins. The driving force behind this development has been three-fold. First, a technical renaissance has enabled high-yielding (>1 g/L) and long-lasting ( $>10 \mathrm{~h}$ in batch operation) CFPS in systems derived from Escherichia coli. Second, the efficiency of orthogonal translation systems (OTSs) has improved. Third, the open nature of the CFPS platform has brought about an unprecedented level of control and freedom of design. Here, we review recent developments in CFPS platforms designed to precisely incorporate NSAAs. In the coming years, we anticipate that CFPS systems will impact efforts to elucidate structure/function relationships of proteins and to make biomaterials and sequence-defined biopolymers for medical and industrial applications.

Keywords: non-standard amino acids, cell-free protein synthesis, synthetic biology, sequence-defined polymers, genome engineering

\section{INTRODUCTION}

The incorporation of non-standard amino acids (NSAAs) into proteins and (poly)peptide-based materials is a key emerging application area in synthetic biology (Liu and Schultz, 2010; Hoesl and Budisa, 2012). In recent years, efforts to incorporate NSAAs using cell-free protein synthesis (CFPS) systems based on Escherichia coli have grown significantly. In this minireview, we discuss these efforts, beginning with a description of the molecular basis for NSAA incorporation in E. coli using orthogonal translation systems (OTSs). We then describe CFPS and recent improvements in NSAA incorporation in crude cell extract as well as reconstituted systems of purified components. Finally, we discuss emerging frontiers and opportunities for CFPS.

\section{NSAA INCORPORATION}

To date, over 100 OTSs have been established for site-specific incorporation of NSAAs into proteins (O'Donoghue et al., 2013). Site-specific NSAA incorporation has been used to expand our understanding of biological systems by enabling studies of protein structure and dynamics with unique IR and X-ray diffraction signatures, fluorescent probes, and photocages (Liu and Schultz, 2010). In other examples, cross-linkable NSAAs have been incorporated to characterize protein-protein and proteinnucleic acid interactions (Liu and Schultz, 2010). In addition to expanding the chemistry of biomolecular systems, NSAA technology has also enabled researchers to mimic post-translational modifications of eukaryotic proteins in bacterial protein expression systems. In an exemplary model, site-specific acetylation of recombinant histones by genetically encoding acetyl-lysine (AcK) elucidated new mechanistic understanding (Neumann et al., 2009).

Beyond fundamental science, NSAA incorporation has also opened the way to novel biopolymer materials, enzymes, and therapeutics which are difficult-if not impossible- to create by other means. Antibody drug conjugates (Zimmerman et al., 2014), modified human therapeutics (Cho et al., 2011), tethered enzymes (Smith et al., 2013), protein polymers (Albayrak and Swartz, in press), phosphoproteins (Park et al., 2011), and selenoproteins (Bröcker et al., 2014) showcase the power of NSAA incorporation. In one example, pegylated human growth hormone showed improved potency and reduced injection frequency (Cho et al., 2011). In another case, an Anti-Her2 antibody bearing p-acetyl-L-phenylalanine enabled precise control of conjugation site and stoichiometry for selective and efficient conjugation to an anti-cancer drug resulting in enhanced tumor regression (Axup et al., 2012). These and other recent breakthroughs highlight exciting opportunities for expanding the chemistry of life.

To incorporate NSAAs site-specifically into proteins, OTSs require (re-)assignment of codons to NSAAs, NSAA-transfer RNA (tRNA) substrates, and ribosome selection of these nonnatural substrates into the catalytic center. So far, ribosome accommodation of NSAAs has not been the limiting factor. Rather, strategies to provide for efficient and accurate incorporation of NSAA-tRNA substrates have been the biggest challenge. In practice, this is usually achieved by using orthogonal tRNA (o-tRNA)/aminoacyl-tRNA synthetase (o-aaRS) pairs from phylogenetically distant organisms (Kim et al., 2013). For example, an engineered tRNA $\mathrm{CUA}_{\mathrm{CH}}^{\mathrm{Ty}} / \mathrm{TyrRS}$ pair derived from Methanocaldococcus jannaschii is used frequently for NSAA 
incorporation (Wang et al., 2001). More recent expansions of the technology have used variants of the pyrrolysine translation system, tRNA ${ }_{\mathrm{CUA}}^{\mathrm{Pyl}} / \mathrm{PylRS}$ from Methanosarcinaceae species (Polycarpo et al., 2006; Wang et al., 2012c). There are many seminal works of orthogonal pairs that have been developed for NSAA incorporation to help drive the field forward (Hughes and Ellington, 2010; Wan et al., 2010; Young et al., 2011; Bianco et al., 2012; Wang et al., 2012a,b; Ko et al., 2013; Lee et al., 2013; Niu et al., 2013; Bröcker et al., 2014; Ma et al., 2014). For codon selection, researchers tend to incorporate NSAAs in response to a non-sense stop codon or quadruplet codon (Wang et al., 2007; Neumann et al., 2010; Niu et al., 2013). The amber codon (TAG) has been the most widely used, because of its low frequency as a stop signal compared to other stop codons (TAA, TGA) (Hoesl and Budisa, 2012).

Figure 1 shows a cartoon representation of an OTS for amber suppression. It also highlights the systems biology challenges associated with NSAA incorporation (O'Donoghue et al., 2013). The orthogonal synthetases have poor catalytic efficiency (Tanrikulu et al., 2009; Nehring et al., 2012; Umehara et al., 2012). Elongation Factor $\mathrm{Tu}$ (EF-Tu) has a limited capability to incorporate bulky or charged NSAAs (Park et al., 2011; O’Donoghue et al., 2013). The presence of release factor 1 (RF1) can cause early termination of proteins when using amber suppression technology (Johnson et al., 2011; Hong et al., 2014). Recent advances have addressed some of these challenges by improving NSAA incorporation efficiency by engineering o-tRNA (Young et al., 2010; Chatterjee et al., 2012), o-aaRS (Liu et al., 1997; Chatterjee et al., 2012), or EF-Tu (Doi et al., 2007; Park et al., 2011) as well as controlling transcription and translation rate (Young et al., 2010; Chatterjee et al., 2013), and removing RF1 competition (Mukai et al., 2010; Johnson et al., 2011; Loscha et al., 2012; Lajoie et al., 2013). While further efforts to re-engineer translation are still needed, these improvements are accelerating rapid growth in synthetic biology efforts to "upgrade protein synthesis" (O'Donoghue et al., 2013). The bulk of this work is being carried out in vivo; however, complementary in vitro systems are also emerging, which we focus on below.

\section{CELL-FREE PROTEIN SYNTHESIS}

CFPS is the synthesis of proteins in vitro without using intact, living cells (Jewett et al., 2008; Caschera and Noireaux, 2014). Over the last 50 years, CFPS systems have significantly advanced our ability to understand, exploit, and expand the capabilities of biological systems (Carlson et al., 2012; Swartz, 2012; Murray and Baliga, 2013). As a complement to in vivo systems, CFPS systems offer some interesting benefits. First, the open environment of the reaction allows the user to directly influence the biochemical systems of interest and as a result, new components can be added or synthesized and can be maintained at precise concentrations (Figure 2). For example, NSAAs that do not enter the cell can be utilized in CFPS. Second, cell-free systems are not constrained by cell-viability requirements, allowing protein synthesis to proceed with otherwise toxic reagents or protein products. Third, CFPS systems can use linear DNA fragments (e.g., PCR products) for a target gene expression, which avoids time-consuming gene cloning steps commonly required for in vivo protein synthesis.
Finally, from a biomanufacturing perspective, cell-free systems separate catalyst synthesis (cell growth) from catalyst utilization (protein production) (Swartz, 2012). This concept represents a significant departure from cell-based processes that rely on microscopic cellular "reactors."

Although CFPS technologies offer many exciting advantages, challenges remain that provide opportunity for improvement. For example, CFPS platforms still have few examples industrially. In addition, cell lysis procedures can be difficult to standardize, leading to different extract performance and limited reaction scales for academic research labs. Thus, while protein yields $(\mathrm{mg} / \mathrm{L})$ are often higher in CFPS, the total amount of protein purified from cells in research labs is typically more because the reaction scales are greater. Despite these challenges, the advantages of CFPS are stimulating new application areas. Dominant amongst these are high-throughput protein production (Calhoun and Swartz, 2005; Swartz, 2012; Catherine et al., 2013; Chappell et al., 2013; Murray and Baliga, 2013), clinical manufacture of protein therapeutics (Murray and Baliga, 2013), genetic circuit optimization (Shin and Noireaux, 2012), the construction of synthetic ribosomes (Jewett et al., 2013), and incorporation of NSAAs (Goerke and Swartz, 2009; Bundy and Swartz, 2010; Ugwumba et al., 2010; Mukai et al., 2011; Ugwumba et al., 2011; Loscha et al., 2012; Albayrak and Swartz, 2013a; Hong et al., 2014; Shrestha et al., 2014).

\section{CRUDE EXTRACT-BASED CFPS FOR NSAA INCORPORATION}

Efforts to use crude extract-based CFPS for the production of proteins containing single and multiple NSAAs are rapidly increasing. Key advances have centered on optimizing the performance of OTSs, expressing the OTS components in the source strain to create one-pot reactions, and removing RF1 competition.

\section{OTS OPTIMIZATION}

The Swartz group has made marked contributions to CFPS development for high yielding NSAA incorporation (Goerke and Swartz, 2009; Bundy and Swartz, 2010). Showcasing the freedom of design in adjusting cell-free system components by direct addition to the reaction, their approach typically adds the NSAA and its purified o-aaRS directly to the reaction, while the o-tRNA is expressed during the cell growth prior to making the extract. As compared to in vivo systems, an advantage of this approach is that the toxicity associated with overexpressing the o-tRNA and $\mathrm{o}$-aaRS is not observed. This is because the OTS elements are sequestered from each other until the protein synthesis reaction. Another advantage is that NSAAs with low solubility or poor transport characteristics can be used. For example, the tyrosine analog $p$-propargyloxy-L-phenylalanine $(\mathrm{pPaF})$, which can be used in site-specific bioconjugation with the copper-catalyzed azide-alkyne cycloaddition, has low solubility. This is a known limitation in vivo. However, site-specific $\mathrm{pPaF}$ incorporation in the CFPS reaction was improved $\sim 27$-fold (as based on protein yield) for producing a modified protein when compared to previous in vivo approach (Bundy and Swartz, 2010).

Cell-free systems are not only useful for making protein product but also for assessing the catalytic efficiency of the 


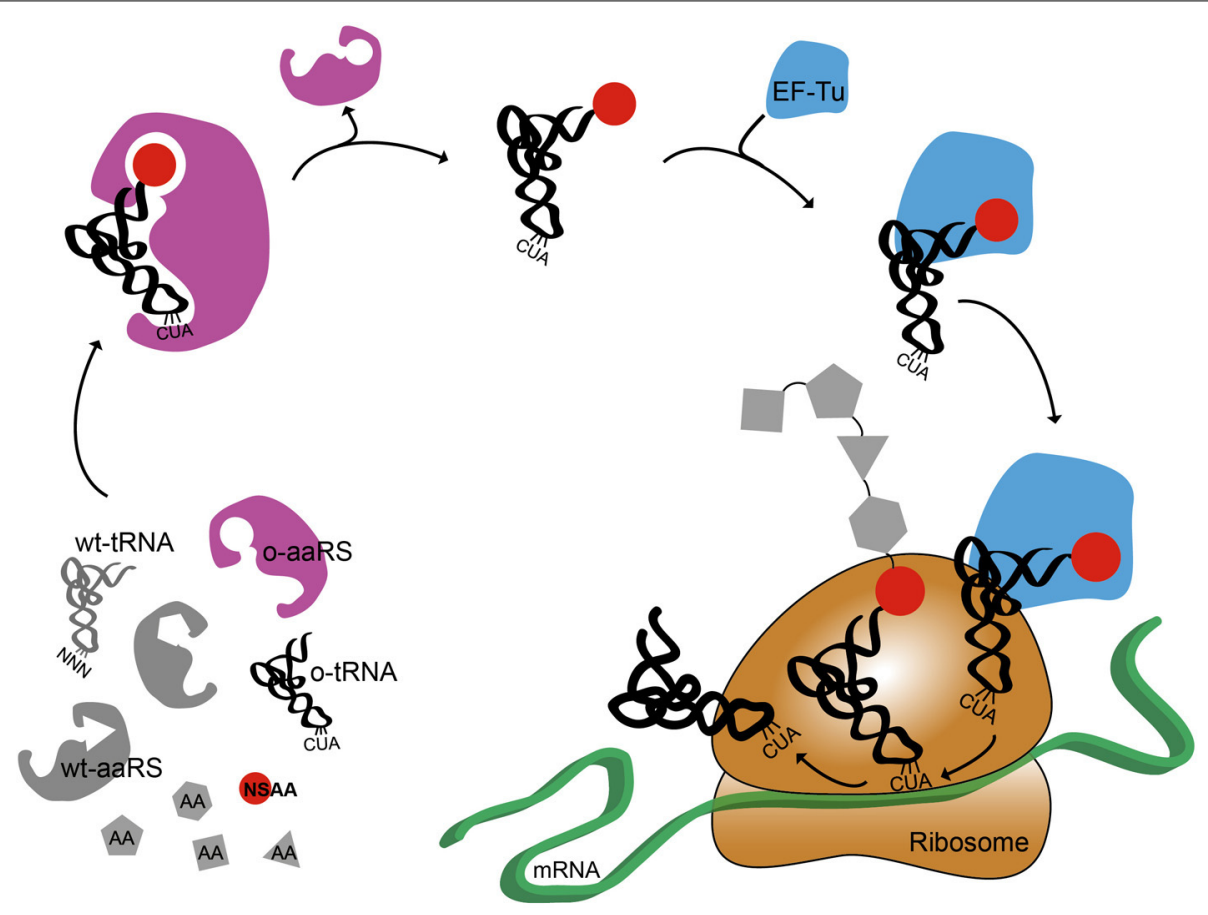

FIGURE 1 | Schematic representation of non-standard amino acid incorporation using an orthogonal translation system.

Orthogonal aminoacyl tRNA synthetase, o-aaRS; orthogonal tRNA, o-tRNA; wild-type aminoacyl tRNA synthetase, wt-aaRS; wild-type
tRNA, wt-tRNA; elongation factor Tu, EF-Tu,; non-standard amino acid, NSAA. Anti-codon sequence on wt-tRNA is NNN, where $N$ is $A, C, G$, or $U$. Anti-amber codon sequence on o-tRNA is CUA.
OTSs. A growing number of studies, for example, have shown that o-aaRSs are poor catalysts, up to 1000 times worse than natural aminoacyl tRNA synthetases, mainly due to the fact that the evolution of the orthogonal pairs occurs under high concentrations of non-standard amino acids (Tanrikulu et al., 2009; Nehring et al., 2012; Umehara et al., 2012; Albayrak and Swartz, 2013b). Future efforts for improving site-specific NSAA incorporation will require the development of o-aaRSs with higher catalytic rates and stronger affinity for the o-tRNAs. One approach to achieve such desired properties is to find strategies to remove fitness and the health of the cell on evolutionary outcomes. Ellington's lab recently published such an approach, compartmentalized partnered replication (Ellefson et al., 2014), but there are other opportunities as well.

In the meantime, NSAA incorporation in cell-free systems is being improved by increasing the amount of o-tRNA and oaaRS in the CFPS reaction. One approach to achieving increased o-tRNA levels was pioneered by Albayrak and Swartz (2013a) and validated by Hong et al. (2014). Namely, the o-tRNA is coproduced in the CFPS reaction as a transzyme construct. The transzyme construct is a DNA fragment containing hammer-head ribozyme sequence between T7-controlled promoter and o-tRNA sequences. Upon transcription, the hammer-head ribozyme cleaves $5^{\prime}$-end of tRNA liberating active tRNA into the reaction (Fechter et al., 1998) and thereby increased o-tRNA is supplied to the CFPS reaction. With the transzyme technology, up to 0.9$1.7 \mathrm{mg} / \mathrm{mL}$ of a modified protein containing NSAA was produced (Albayrak and Swartz, 2013a) and multiple site NSAA incorporation was improved (Hong et al., 2014). As another approach, there are efforts to co-express all the OTS components in the source strain. While there are potential concerns of expressing both the o-tRNA and the o-aaRS in the source strain prior to lysis, Bundy and colleagues recently showed that this was not only possible, but improved CFPS yields of a modified protein (Smith et al., 2014). As an alternative approach, natural amino acids have been depleted from crude extracts to allow for the incorporation of NSAA analogs (Singh-Blom et al., 2014).

\section{REMOVING RF1 COMPETITION}

NSAA incorporation using amber codon suppression is limited by RF1 competition (Lajoie et al., 2013). The presence of RF1 causes the production of truncated protein and low yields of protein product in the case of multiple identical site-specific NSAA incorporation (Park et al., 2011; Hong et al., 2014). Deletion of RF1 is lethal in native biological systems. However, this limitation was recently addressed by making a more promiscuous release factor 2 (Johnson et al., 2011, 2012), and genome engineering (Mukai et al., 2010; Heinemann et al., 2012; Ohtake et al., 2012). Most notably, the development of the first genomically recoded E. coli strain was completed; all 321 TAG stop codons were reassigned to synonymous TAA codons allowing the deletion of RF1 without observing growth defects (Lajoie et al., 2013).

With RF1-deficient E. coli strains at hand, efforts are underway to utilize these strains in vivo for improved production of proteins with NSAAs, but also to develop RF1-deficient CFPS systems. In one example, human histone $\mathrm{H} 4$ protein was produced with site-specific incorporation of AcK at four amber sites by using a RF1-deficient cell extract (Mukai et al., 2011). In another 


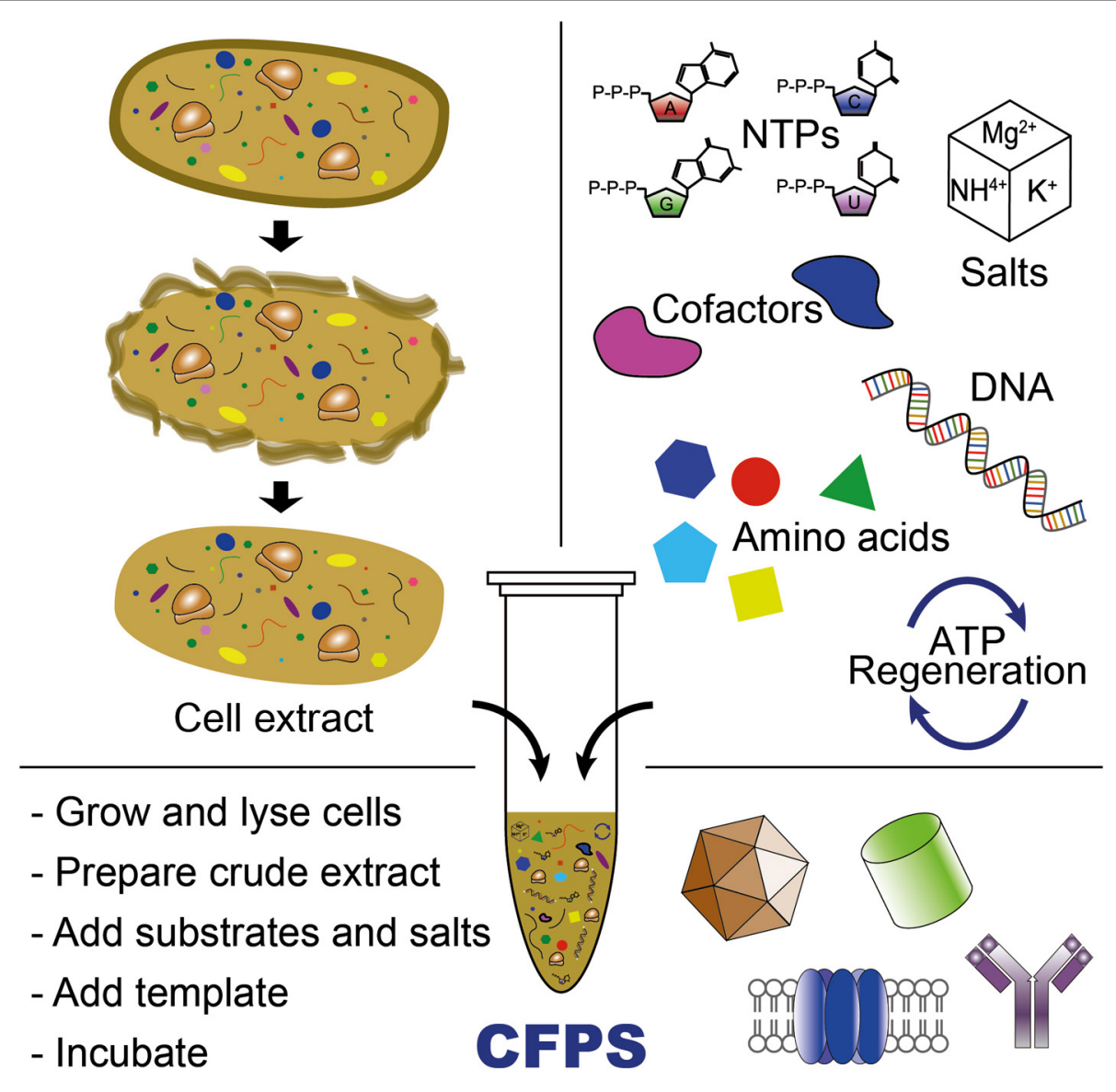

FIGURE 2 | Cell-free protein synthesis system for producing proteins or (poly)peptide-based materials. CFPS requires cell extract, an energy regeneration system, and chemical substrates and salts (e.g., NTPs, amino acids, salts, and cofactors). Cell-free transcription and translation is initiated by adding DNA template (plasmid or PCR-amplified linear DNA templates) into the CFPS reaction. case, the effect of RF1 deletion was systematically assessed for single and multiple site $\mathrm{pPaF}$ incorporation using cell extracts from genomically recoded $E$. coli with or without RF1 (Hong et al., 2014). The production of modified soluble superfolder green fluorescent protein ( $\mathrm{sfGFP}$ ) containing $\mathrm{pPaF}$ was 2.5 -fold higher in the RF1-deficient cell extract compared to the RF1-present cell extract. The authors showed that the yield improvement was due to an increase in full-length modified sfGFP synthesis, observing a shift from $20 \%$ full-length product (with RF1) to $80 \%$ full-length product (without RF1). In a complementary approach, RF1depleted cell extracts were constructed from selective removal of a RF1 variant tagged with chitin-binding domains (Loscha et al., 2012) or His-tag (Gerrits et al., 2007). Looking forward, we anticipate that RF1-deficient $E$. coli strains will become an important chassis for NSAA incorporation.

\section{RECONSTITUTED IN VITRO TRANSLATION FOR NSAA INCORPORATION}

Although crude extract-based CFPS systems have shown tremendous growth, there are limitations to the number of open coding channels available because one must grow E. coli to obtain cellular lysate. To address this limitation, researchers have turned to purified translation systems, such as the PURE system (protein synthesis using purified recombinant elements) (Shimizū et al., 2001). Since the user defines all of the elements in the PURE system, single or multiple components (e.g., tRNA, aaRS) can be omitted, increased, or decreased according to the experimental purpose (Hirao et al., 2009). This enables highly efficient sense and non-sense suppression and provides unmatched flexibility for genetic code reprogramming to incorporate NSAAs (Shimizu et al., 2005). Efforts using purified translation for NSAA incorporation have mainly centered on the production, screening, and selection of peptidomimetic, or non-standard peptides (Josephson et al., 2005; Tan et al., 2005; Hartman et al., 2007; Passioura and Suga, 2013). As an exemplary illustration, peptidomimetic synthesis was achieved by adding pre-aminoacylated tRNA with NSAAs corresponding to sense codons in the reconstituted translation system lacking aaRS activities (Forster et al., 2003). In an alternative approach, Suga's group has leveraged the highly flexible tRNA acylation Flexizyme technology. Flexizyme is an artificial ribozyme that was developed to charge virtually any amino acid onto any tRNA in vitro, allowing the synthesis of proteins and short peptides containing multiple distinct NSAAs (Murakami et al., 2006; Ohuchi et al., 2007). A drug discovery 
pipeline has been enabled by combining a modified reconstituted translation system with Flexizyme technology (Goto et al., 2011) for the development of small peptides (Passioura and Suga, 2013), such as macrocyclic peptides (Hayashi et al., 2012; Morimoto et al., 2012). In yet a different approach, Szostak's work has demonstrated the ability to incorporate numerous amino acid analogs using the endogenous machinery. Strikingly, the natural aaRS machinery tolerates many kinds of side chain derivatives, such as $\alpha, \alpha$ disubstituted, $N$-methyl and $\alpha$-hydroxy derivatives (Hartman et al., 2007). Even D-amino acids have been shown to be compatible with polypeptide elongation (Fujino et al., 2013).

Although PURE translation is a powerful research tool, the cost of the PURE system is prohibitive for most commercial applications. For example, when compared to crude extract-based CFPS systems, which have been scaled to $100 \mathrm{~L}$ (Zawada et al., 2011), the PURE system costs $\sim 1000$ times more on a milligram protein produced/\$ basis (Hong et al., 2014) and yields lower protein titers than the crude extract-based CFPS system (Lee et al., 2012; Hong et al., 2014). Hence, an important design decision for producing proteins with NSAAs using cell-free systems is choosing between a crude extract and a purified system.

\section{EMERGING APPLICATIONS}

Marked advancements in productivity, improvements in OTS efficiency, and increases in the ability to incorporate multiple identical NSAAs (in crude extracts) and multiple distinct NSAAs (in the PURE system) are rapidly expanding the possible applications of CFPS systems. In this section, we highlight several emerging applications made possible by these advances. These include the production of protein-based materials and therapeutics.

\section{PROTEIN-BASED MATERIALS}

NSAA incorporation is being applied to create new types of sequence-defined polymers for versatile applications in biomaterials synthesis. In an illustrative example, Albayrak and Swartz reported direct polymerization of proteins containing two or three copies of site-specifically incorporated NSAAs that allows copper-catalyzed azide-alkyne cycloaddition to form linear or branched protein polymers (Albayrak and Swartz, in press).

\section{THERAPEUTICS}

NSAA incorporation is being applied to (i) clinical scale production of protein therapeutics and vaccines, (ii) discovery of novel biologics through ribosome display methods (Murray and Baliga, 2013), and (iii) structure/function studies to identify protein inhibitors. Swartz and colleagues, for example, have developed a novel pipeline for the production of decorated virus-like particles that could function as potential vaccines and imaging agents (Lu et al., 2013). In another example, Sutro Biopharma has demonstrated the synthesis of site-specific antibody drug conjugates (ADCs) (Zimmerman et al., 2014). Their ADCs, which were synthesized at $\sim 250 \mu \mathrm{g} / \mathrm{mL}$ titers, proved potent in cell cytotoxicity assays. Rather than producing a therapeutic using CFPS, Ugwumba et al. utilized the NSAA 7-(hydroxy-coumarin4-yl) ethylglycine to structurally probe a protein from the West Nile Virus to identify novel inhibitors (Ugwumba et al., 2011). Collectively, these recent reports highlight the utility of CFPS for producing novel vaccines and therapeutics, as well for serving as a rapid and attractive tool in drug discovery.

\section{CONCLUSION AND OUTLOOK}

CFPS has emerged as a promising approach to enable site-specific incorporation of NSAAs into proteins and bio-based polymers. With the ability to select peptides and proteins for novel drugs in the PURE system and advent of scalable CFPS from crude extract systems, we anticipate significant growth in the field in years to come. Immediate challenges are (i) the evolution of more efficient OTSs (ii) new codons that can be assigned to NSAAs, and (iii) the development of genomically recoded organisms for preparing highly active cellular extracts. Addressing these challenges and continuing to lower costs will expand the scale and scope of cellfree biology, providing a transformative toolbox that enables new frontiers in synthetic biology.

\section{ACKNOWLEDGMENTS}

This work was supported by the National Science Foundation (MCB-0943393), the Office of Naval Research (N0001411-1-0363), the DARPA YFA Program (N66001-11-1-4137), the Army Research Office (W911NF- 11-1-044), the NSF Materials Network Grant (DMR - 1108350), the DARPA Living Foundries Program (N66001-12-C-4211), the David and Lucile Packard Foundation (2011-37152), and the Chicago Biomedical Consortium with support from the Searle Funds at the Chicago Community Trust for support. We thank Dr. Javin Oza for critical reading of the manuscript.

\section{REFERENCES}

Albayrak, C., and Swartz, J. R. (2013a). Cell-free co-production of an orthogonal transfer RNA activates efficient site-specific non-natural amino acid incorporation. Nucleic Acids Res. 41, 5949-5963. doi: 10.1093/nar/gkt226

Albayrak, C., and Swartz, J. R. (2013b). Using E. coli-based cell-free protein synthesis to evaluate the kinetic performance of an orthogonal tRNA and aminoacyltRNA synthetase pair. Biochem. Biophys. Res. Commun. 431, 291-295. doi: 10.1016/j.bbrc.2012.12.108

Albayrak, C., and Swartz, J. R. (in press). Direct polymerization of proteins. ACS Synth. Biol. doi: 10.1021/sb400116x

Axup, J. Y., Bajjuri, K. M., Ritland, M., Hutchins, B. M., Kim, C. H., Kazane, S. A., et al. (2012). Synthesis of site-specific antibody-drug conjugates using unnatural amino acids. Proc. Natl. Acad. Sci. U.S.A. 109, 16101-16106. doi: 10.1073/pnas.1211023109

Bianco, A., Townsley, F. M., Greiss, S., Lang, K., and Chin, J. W. (2012). Expanding the genetic code of Drosophila melanogaster. Nat. Chem. Biol. 8, 748-750. doi: 10.1038/nchembio. 1043

Bröcker, M. J., Ho, J. M. L., Church, G. M., Söll, D., and O’Donoghue, P. (2014). Recoding the genetic code with selenocysteine. Angew. Chem. Int. Ed. Engl. 53, 319-323. doi: 10.1002/anie.201308584

Bundy, B. C., and Swartz, J. R. (2010). Site-specific incorporation of $p$ propargyloxyphenylalanine in a cell-free environment for direct protein-protein click conjugation. Bioconjug. Chem. 21, 255-263. doi: 10.1021/bc9002844

Calhoun, K. A., and Swartz, J. R. (2005). Energizing cell-free protein synthesis with glucose metabolism. Biotechnol. Bioeng. 90, 606-613. doi: 10.1002/bit.20449

Carlson, E. D., Gan, R., Hodgman, C. E., and Jewett, M. C. (2012). Cell-free protein synthesis: applications come of age. Biotechnol. Adv. 30, 1185-1194. doi: 10.1016/j.biotechadv.2011.09.016

Caschera, F., and Noireaux, V. (2014). Synthesis of $2.3 \mathrm{mg} / \mathrm{ml}$ of protein with an all Escherichia coli cell-free transcription-translation system. Biochimie 99, 162-168. doi: 10.1016/j.biochi.2013.11.025

Catherine, C., Lee, K.-H., Oh, S.-J., and Kim, D.-M. (2013). Cell-free platforms for flexible expression and screening of enzymes. Biotechnol. Adv. 31, 797-803. doi: 10.1016/j.biotechadv.2013.04.009 
Chappell, J., Jensen, K., and Freemont, P. S. (2013). Validation of an entirely in vitro approach for rapid prototyping of DNA regulatory elements for synthetic biology. Nucleic Acids Res. 41, 3471-3481. doi: 10.1093/nar/gkt052

Chatterjee, A., Sun, S. B., Furman, J. L., Xiao, H., and Schultz, P. G. (2013). A versatile platform for single- and multiple-unnatural amino acid mutagenesis in Escherichia coli. Biochemistry 52, 1828-1837. doi: 10.1021/bi4000244

Chatterjee, A., Xiao, H., and Schultz, P. G. (2012). Evolution of multiple, mutually orthogonal prolyl-tRNA synthetase/tRNA pairs for unnatural amino acid mutagenesis in Escherichia coli. Proc. Natl. Acad. Sci. U.S.A. 109, 14841-14846. doi: 10.1073/pnas.1212454109

Cho, H., Daniel, T., Buechler, Y. J., Litzinger, D. C., Maio, Z., Putnam, A.-M. H., et al. (2011). Optimized clinical performance of growth hormone with an expanded genetic code. Proc. Natl. Acad. Sci. U.S.A. 108, 9060-9065. doi: 10.1073/pnas. 1100387108

Doi, Y., Ohtsuki, T., Shimizu, Y., Ueda, T., and Sisido, M. (2007). Elongation factor Tu mutants expand amino acid tolerance of protein biosynthesis system. J. Am. Chem. Soc. 129, 14458-14462. doi: 10.1021/ja075557u

Ellefson, J. W., Meyer, A. J., Hughes, R. A., Cannon, J. R., Brodbelt, J. S., and Ellington, A. D. (2014). Directed evolution of genetic parts and circuits by compartmentalized partnered replication. Nat. Biotechnol. 32, 97-101. doi: $10.1038 /$ nbt. 2714

Fechter, P., Rudinger, J., Giegé, R., and Théobald-Dietrich, A. (1998). Ribozyme processed tRNA transcripts with unfriendly internal promoter for T7 RNA polymerase: production and activity. FEBS Lett. 436, 99-103. doi: 10.1016/S00145793(98)01096-5

Forster, A. C., Tan, Z., Nalam, M. N. L., Lin, H., Qu, H., Cornish, V. W., et al. (2003). Programming peptidomimetic syntheses by translating genetic codes designed de novo. Proc. Natl. Acad. Sci. U.S.A. 100, 6353-6357. doi: 10.1073/pnas.1132122100

Fujino, T., Goto, Y., Suga, H., and Murakami, H. (2013). Reevaluation of the damino acid compatibility with the elongation event in translation. J. Am. Chem. Soc. 135, 1830-1837. doi: 10.1021/ja309570x

Gerrits, M., Strey, J., Claußnitzer, I., Groll, U. V., Schäfer, F., Rimmele, M. et al. (2007). "Cell-free synthesis of defined protein conjugates by site-directed cotranslational labeling," in Cell-Free Protein Expression, eds W. Kudlicki, F. Katzen, and R. Bennett (Austin, TX: Landes Bioscience), 166-180.

Goerke, A. R., and Swartz, J. R. (2009). High-level cell-free synthesis yields of proteins containing site-specific non-natural amino acids. Biotechnol. Bioeng. 102, 400-416. doi: 10.1002/bit.22070

Goto, Y., Katoh, T., and Suga, H. (2011). Flexizymes for genetic code reprogramming. Nat. Protoc. 6, 779-790. doi: 10.1038/nprot.2011.331

Hartman, M. C. T., Josephson, K., Lin, C.-W., and Szostak, J. W. (2007). An expanded set of amino acid analogs for the ribosomal translation of unnatural peptides. PLoS ONE 2:e972. doi: 10.1371/journal.pone.0000972

Hayashi, Y., Morimoto, J., and Suga, H. (2012). In vitro selection of anti-Akt2 thioether-macrocyclic peptides leading to isoform-selective inhibitors. ACS Chem. Biol. 7, 607-613. doi: 10.1021/cb200388k

Heinemann, I. U., Rovner, A. J., Aerni, H. R., Rogulina, S., Cheng, L., Olds, W., et al. (2012). Enhanced phosphoserine insertion during Escherichia coli protein synthesis via partial UAG codon reassignment and release factor 1 deletion. FEBS Lett. 586, 3716-3722. doi: 10.1016/j.febslet.2012.08.031

Hirao, I., Kanamori, T., and Ueda, T. (2009). "Cell-free synthesis of proteins with unnatural amino acids. The PURE system and expansion of the genetic code," in Protein Engineering, eds C. Köhrer and U. Rajbhandary (Heidelberg: Springer Berlin), 271-290.

Hoesl, M. G., and Budisa, N. (2012). Recent advances in genetic code engineering in Escherichia coli. Curr. Opin. Biotechnol. 23, 751-757. doi: 10.1016/j.copbio.2011.12.027

Hong, S. H., Ntai, I., Haimovich, A. D., Kelleher, N. L., Isaacs, F. J., and Jewett, M. C. (2014). Cell-free protein synthesis from a release factor 1 deficient Escherichia coli activates efficient and multiple site-specific nonstandard amino acid incorporation. ACS Synth. Biol. doi: 10.1021/sb400140t. [Epub ahead of print].

Hughes, R. A., and Ellington, A. D. (2010). Rational design of an orthogonal tryptophanyl nonsense suppressor tRNA. Nucleic Acids Res. 38, 6813-6830. doi: 10.1093/nar/gkq521

Jewett, M. C., Calhoun, K. A., Voloshin, A., Wuu, J. J., and Swartz, J. R. (2008). An integrated cell-free metabolic platform for protein production and synthetic biology. Mol. Syst. Biol. 4, 220. doi: 10.1038/msb.2008.57
Jewett, M. C., Fritz, B. R., Timmerman, L. E., and Church, G. M. (2013). In vitro integration of ribosomal RNA synthesis, ribosome assembly, and translation. Mol. Syst. Biol. 9, 678. doi: 10.1038/msb.2013.31

Johnson, D. B. F., Wang, C., Xu, J., Schultz, M. D., Schmitz, R. J., Ecker, J. R., et al. (2012). Release factor one is nonessential in Escherichia coli. ACS Chem. Biol. 7, 1337-1344. doi: 10.1021/cb300229q

Johnson, D. B. F., Xu, J., Shen, Z., Takimoto, J. K., Schultz, M. D., Schmitz, R J., et al. (2011). RF1 knockout allows ribosomal incorporation of unnatural amino acids at multiple sites. Nat. Chem. Biol. 7, 779-786. doi: 10.1038/ nchembio. 657

Josephson, K., Hartman, M. C. T., and Szostak, J. W. (2005). Ribosomal synthesis of unnatural peptides. J. Am. Chem. Soc. 127, 11727-11735. doi: 10.1021/ja0515809

Kim, C. H., Axup, J. Y., and Schultz, P. G. (2013). Protein conjugation with genetically encoded unnatural amino acids. Curr. Opin. Chem. Biol. 17, 412-419. doi: 10.1016/j.cbpa.2013.04.017

Ko, J.-h., Llopis, P. M., Heinritz, J., Jacobs-Wagner, C., and Söll, D. (2013) Suppression of amber codons in Caulobacter crescentus by the orthogonal Escherichia coli histidyl-tRNA synthetase/tRNA ${ }^{\text {His }}$ Pair. PLoS ONE 8:e83630. doi: 10.1371/journal.pone.0083630

Lajoie, M. J., Rovner, A. J., Goodman, D. B., Aerni, H.-R., Haimovich, A. D., Kuznetsov, G., et al. (2013). Genomically recoded organisms expand biological functions. Science 342, 357-360. doi: 10.1126/science.1241459

Lee, K. B., Kim, H.-C., Kim, D.-M., Kang, T. J., and Suga, H. (2012). Comparative evaluation of two cell-free protein synthesis systems derived from Escherichia coli for genetic code reprogramming. J. Biotechnol. 164, 330-335. doi: 10.1016/j.jbiotec.2013.01.011

Lee, S., Oh, S., Yang, A., Kim, J., Söll, D., Lee, D., et al. (2013). A facile strategy for selective incorporation of phosphoserine into histones. Angew. Chem. Int. Ed. Engl. 52, 5771-5775. doi: 10.1002/anie.201300531

Liu, C. C., and Schultz, P. G. (2010). Adding new chemistries to the genetic code. Annu. Rev. Biochem. 79, 413-444. doi: 10.1146/annurev.biochem.052308.105824

Liu, D. R., Magliery, T. J., Pastrnak, M., and Schultz, P. G. (1997). Engineering a tRNA and aminoacyl-tRNA synthetase for the site-specific incorporation of unnatural amino acids into proteins in vivo. Proc. Natl. Acad. Sci. U.S.A. 94, 10092-10097. doi: 10.1073/pnas.94.19.10092

Loscha, K. V., Herlt, A. J., Qi, R., Huber, T., Ozawa, K., and Otting, G. (2012). Multiple-site labeling of proteins with unnatural amino acids. Angew. Chem. Int. Ed. Engl. 51, 2243-2246. doi: 10.1002/anie.201108275

Lu, Y., Welsh, J. P., Chan, W., and Swartz, J. R. (2013). Escherichia coli-based cell free production of flagellin and ordered flagellin display on virus-like particles. Biotechnol. Bioeng. 110, 2073-2085. doi: 10.1002/bit.24903

Ma, Y., Biava, H., Contestabile, R., Budisa, N., and di Salvo, M. L. (2014). Coupling bioorthogonal chemistries with artificial metabolism: intracellular biosynthesis of azidohomoalanine and its incorporation into recombinant proteins. Molecules 19, 1004-1022. doi: 10.3390/molecules19011004

Morimoto, J., Hayashi, Y., and Suga, H. (2012). Discovery of macrocyclic peptides armed with a mechanism-based warhead: isoform-selective inhibition of human deacetylase SIRT2. Angew. Chem. Int. Ed. Engl. 51, 3423-2427. doi: 10.1002/anie.201108118

Mukai, T., Hayashi, A., Iraha, F., Sato, A., Ohtake, K., Yokoyama, S., et al. (2010). Codon reassignment in the Escherichia coli genetic code. Nucleic Acids Res. 38, 8188-8195. doi: 10.1093/nar/gkq707

Mukai, T., Yanagisawa, T., Ohtake, K., Wakamori, M., Adachi, J., Hino, N., et al. (2011). Genetic-code evolution for protein synthesis with nonnatural amino acids. Biochem. Biophys. Res. Commun. 411, 757-761. doi: 10.1016/j.bbrc.2011.07.020

Murakami, H., Ohta, A., Ashigai, H., and Suga, H. (2006). A highly flexible tRNA acylation method for non-natural polypeptide synthesis. Nat. Methods 3, 357-359. doi: 10.1038/nmeth877

Murray, C. J., and Baliga, R. (2013). Cell-free translation of peptides and proteins: from high throughput screening to clinical production. Curr. Opin. Chem. Biol. 17, 420-426. doi: 10.1016/j.cbpa.2013.02.014

Nehring, S., Budisa, N., and Wiltschi, B. (2012). Performance analysis of orthogonal pairs designed for an expanded eukaryotic genetic code. PLoS ONE 7:e31992. doi: 10.1371/journal.pone.0031992

Neumann, H., Hancock, S. M., Buning, R., Routh, A., Chapman, L., Somers, J., et al. (2009). A method for genetically installing site-specific acetylation in 
recombinant histones defines the effects of H3 K56 acetylation. Mol. Cell 36, 153-163. doi: 10.1016/j.molcel.2009.07.027

Neumann, H., Wang, K., Davis, L., Garcia-Alai, M., and Chin, J. W. (2010). Encoding multiple unnatural amino acids via evolution of a quadrupletdecoding ribosome. Nature 464, 441-444. doi: 10.1038/nature08817

Niu, W., Schultz, P. G., and Guo, J. (2013). An expanded genetic code in mammalian cells with a functional quadruplet codon. ACS Chem. Biol. 8, 1640-1645. doi: $10.1021 / \mathrm{cb} 4001662$

O’Donoghue, P., Ling, J., Wang, Y.-S., and Söll, D. (2013). Upgrading protein synthesis for synthetic biology. Nat. Chem. Biol. 9, 594-598. doi: 10.1038/nchembio. 1339

Ohtake, K., Sato, A., Mukai, T., Hino, N., Yokoyama, S., and Sakamoto, K. (2012). Efficient decoding of the UAG triplet as a full-fledged sense codon enhances the growth of a prfA-deficient strain of Escherichia coli. J. Bacteriol. 194, 2606-2613. doi: $10.1128 / J B .00195-12$

Ohuchi, M., Murakami, H., and Suga, H. (2007). The flexizyme system: a highly flexible tRNA aminoacylation tool for the translation apparatus. Curr. Opin. Chem. Biol. 11, 537-542. doi: 10.1016/j.cbpa.2007.08.011

Park, H.-S., Hohn, M. J., Umehara, T., Guo, L.-T., Osborne, E. M., Benner, J., et al. (2011). Expanding the genetic code of Escherichia coli with phosphoserine. Science 333, 1151-1154. doi: 10.1126/science. 1207203

Passioura, T., and Suga, H. (2013). Flexizyme-mediated genetic reprogramming as a tool for noncanonical peptide synthesis and drug discovery. Chem. Eur. J. 19, 6530-6536. doi: 10.1002/chem.201300247

Polycarpo, C. R., Herring, S., Bérubé, A., Wood, J. L., Söll, D., and Ambrogelly, A. (2006). Pyrrolysine analogues as substrates for pyrrolysyl-tRNA synthetase. FEBS Lett. 580, 6695-6700. doi: 10.1016/j.febslet.2006.11.028

Shimizu, Y., Inoue, A., Tomari, Y., Suzuki, T., Yokogawa, T., Nishikawa, K., et al. (2001). Cell-free translation reconstituted with purified components. Nat. Biotechnol. 19, 751-755. doi: 10.1038/90802

Shimizu, Y., Kanamori, T., and Ueda, T. (2005). Protein synthesis by pure translation systems. Methods 36, 299-304. doi: 10.1016/j.ymeth.2005.04.006

Shin, J., and Noireaux, V. (2012). An E. coli cell-free expression toolbox: application to synthetic gene circuits and artificial cells. ACS Synth. Biol. 1, 29-41. doi: $10.1021 / \mathrm{sb} 200016 \mathrm{~s}$

Shrestha, P., Smith, M. T., and Bundy, B. C. (2014). Cell-free unnatural amino acid incorporation with alternative energy systems and linear expression templates. New Biotechnol. 31, 28-34. doi: 10.1016/j.nbt.2013.09.002

Singh-Blom, A., Hughes, R. A., and Ellington, A. D. (2014). An amino acid depleted cell-free protein synthesis system for the incorporation of noncanonical amino acid analogs into proteins. J. Biotechnol. 178, 12-22. doi: 10.1016/j.jbiotec.2014.02.009

Smith, M. T., Hawes, A. K., Shrestha, P., Rainsdon, J. M., Wu, J. C., and Bundy, B. C. (2014). Alternative fermentation conditions for improved Escherichia coli-based cell-free protein synthesis for proteins requiring supplemental components for proper synthesis. Process Biochem. 49, 217-222. doi: 10.1016/j.procbio.2013.10.012

Smith, M. T., Wu, J. C., Varner, C. T., and Bundy, B. C. (2013). Enhanced protein stability through minimally invasive, direct, covalent, and site-specific immobilization. Biotechnol. Prog. 29, 247-254. doi: 10.1002/btpr.1671

Swartz, J. R. (2012). Transforming biochemical engineering with cell-free biology. AIChE J. 58, 5-13. doi: 10.1002/aic.13701

Tan, Z., Blacklow, S. C., Cornish, V. W., and Forster, A. C. (2005). De novo genetic codes and pure translation display. Methods 36, 279-290. doi: 10.1016/j.ymeth.2005.04.011

Tanrikulu, I. C., Schmitt, E., Mechulam, Y., Goddard, W. A., and Tirrell, D. A. (2009). Discovery of Escherichia coli methionyl-tRNA synthetase mutants for efficient labeling of proteins with azidonorleucine in vivo. Proc. Natl. Acad. Sci. U.S.A. 106, 15285-15290. doi: 10.1073/pnas.0905735106

Ugwumba, I. N., Ozawa, K., de la Cruz, L., Xu, Z.-Q., Herlt, A. J., Hadler, K. S., et al. (2011). Using a genetically encoded fluorescent amino acid as a site-specific probe to detect binding of low-molecular-weight compounds. Assay Drug Dev. Technol. 9, 50-57. doi: 10.1089/adt.2010.0306

Ugwumba, I. N., Ozawa, K., Xu, Z.-Q., Ely, F., Foo, J.-L., Herlt, A. J., et al. (2010). Improving a natural enzyme activity through incorporation of unnatural amino acids. J. Am. Chem. Soc. 133, 326-333. doi: 10.1021/ja10 $6416 \mathrm{~g}$

Umehara, T., Kim, J., Lee, S., Guo, L.-T., Söll, D., and Park, H.-S. (2012). NAcetyl lysyl-tRNA synthetases evolved by a CcdB-based selection possess $\mathrm{N}$ acetyl lysine specificity in vitro and in vivo. FEBS Lett. 586, 729-733. doi: 10.1016/j.febslet.2012.01.029

Wan, W., Huang, Y., Wang, Z., Russell, W. K., Pai, P.-J., Russell, D. H., et al. (2010). A facile system for genetic incorporation of two different noncanonical amino acids into one protein in Escherichia coli. Angew. Chem. Int. Ed. Engl. 49, 3211-3214. doi: 10.1002/anie.201000465

Wang, F., Niu, W., Guo, J., and Schultz, P. G. (2012a). Unnatural amino acid mutagenesis of fluorescent proteins. Angew. Chem. Int. Ed. Engl. 51, 10132-10135. doi: 10.1002/anie.201204668

Wang, K., Neumann, H., Peak-Chew, S. Y., and Chin, J. W. (2007). Evolved orthogonal ribosomes enhance the efficiency of synthetic genetic code expansion. Nat. Biotechnol. 25, 770-777. doi: 10.1038/nbt1314

Wang, L., Brock, A., Herberich, B., and Schultz, P. G. (2001). Expanding the genetic code of Escherichia coli. Science 292, 498-500. doi: 10.1126/science. 1060077

Wang, Y.-S., Fang, X., Chen, H.-Y., Wu, B., Wang, Z. U., Hilty, C., et al. (2012b). Genetic incorporation of twelve meta-substituted phenylalanine derivatives using a single pyrrolysyl-tRNA synthetase mutant. ACS Chem. Biol. 8, 405-415. doi: $10.1021 / \mathrm{cb} 300512 \mathrm{r}$

Wang, Y.-S., Fang, X., Wallace, A. L., Wu, B., and Liu, W. R. (2012c). A rationally designed pyrrolysyl-tRNA synthetase mutant with a broad substrate spectrum. J. Am. Chem. Soc. 134, 2950-2953. doi: 10.1021/ja211972x

Young, D. D., Young, T. S., Jahnz, M., Ahmad, I., Spraggon, G., and Schultz, P. G. (2011). An evolved aminoacyl-tRNA synthetase with atypical polysubstrate specificity. Biochemistry 50, 1894-1900. doi: 10.1021/bi101929e

Young, T. S., Ahmad, I., Yin, J. A., and Schultz, P. G. (2010). An enhanced system for unnatural amino acid mutagenesis in E. coli. J. Mol. Biol. 395, 361-374. doi: 10.1016/j.jmb.2009.10.030

Zawada, J. F., Yin, G., Steiner, A. R., Yang, J., Naresh, A., Roy, S. M., et al. (2011). Microscale to manufacturing scale-up of cell-free cytokine production-a new approach for shortening protein production development timelines. Biotechnol. Bioeng. 108, 1570-1578. doi: 10.1002/bit.23103

Zimmerman, E. S., Heibeck, T. H., Gill, A., Li, X., Murray, C. J., Madlansacay, M. R., et al. (2014). Production of site-specific antibody-drug conjugates using optimized non-natural amino acids in a cell-free expression system. Bioconjug. Chem. 25, 351-361. doi: 10.1021/bc400490z

Conflict of Interest Statement: The authors declare that the research was conducted in the absence of any commercial or financial relationships that could be construed as a potential conflict of interest.

Received: 15 March 2014; accepted: 19 May 2014; published online: 10 June 2014. Citation: Hong SH, Kwon Y-C and Jewett MC (2014) Non-standard amino acid incorporation into proteins using Escherichia coli cell-free protein synthesis. Front. Chem. 2:34. doi: $10.3389 /$ fchem.2014.00034

This article was submitted to Chemical Biology, a section of the journal Frontiers in Chemistry.

Copyright $\odot 2014$ Hong, Kwon and Jewett. This is an open-access article distributed under the terms of the Creative Commons Attribution License (CC BY). The use, distribution or reproduction in other forums is permitted, provided the original author(s) or licensor are credited and that the original publication in this journal is cited, in accordance with accepted academic practice. No use, distribution or reproduction is permitted which does not comply with these terms. 